\title{
openheart Sex-stratified analysis of national trends and outcomes in isolated tricuspid valve surgery
}

\author{
Pranav Chandrashekar, ${ }^{1}$ Erin Amanda Fender, ${ }^{1}$ Chad J Zack, ${ }^{1}$ Yogesh N V Reddy, ${ }^{1}$ \\ Courtney E Bennett, ${ }^{1,2}$ Megha Prasad, ${ }^{1}$ Mohammed A Al-Hijji, ${ }^{1}$ John M Stulak, ${ }^{3}$ \\ Virginia M Miller ${ }^{3,4}$
}

\begin{abstract}
- Additional material is published online only. To view please visit the journal online (http://dx.doi.org/10.1136/ openhrt-2017-000719).
\end{abstract}

To cite: Chandrashekar $P$, Fender EA, Zack CJ, et al. Sexstratified analysis of national trends and outcomes in isolated tricuspid valve surgery. Open Heart 2018;5:e000719. doi:10.1136/

openhrt-2017-000719

Received 5 September 2017 Revised 17 November 2017 Accepted 19 November 2017

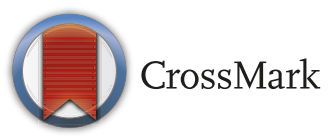

${ }^{1}$ Department of Cardiovascular Diseases, Mayo Clinic, Rochester, Minnesota, USA ${ }^{2}$ Department of Critical Care Medicine, Mayo Clinic, Rochester, Minnesota, USA ${ }^{3}$ Department of Surgery, Mayo Clinic, Rochester, Minnesota, USA

${ }^{4}$ Department of Physiology and Biomedical Engineering, Mayo Clinic, Rochester, Minnesota, USA

\section{Correspondence to} Dr Virginia M Miller; miller. virginia@mayo.edu

\section{ABSTRACT}

Objective Female sex is a known risk factor for cardiac surgery, and tricuspid valve (TV) disease is more common in women. There are few data on sex-stratified surgical outcomes for isolated TV surgery. An administrative database was used to compare acute in-hospital outcomes between men and women undergoing isolated TV surgery.

Methods Patients aged $>18$ who underwent TV repair or replacement from 2004 to 2013 were identified using the National Inpatient Sample. Patients were excluded if they had congenital heart disease, endocarditis, or were undergoing concomitant cardiac surgeries except coronary bypass. Results were weighted to represent national averages. Sex-stratified analysis was performed using propensity score matching to compare in-hospital mortality, postoperative complications and hospital costs. Results Over 10 years, women represented $58 \%$ of the 5005 TV surgeries performed. With propensity matching, hospital mortality $(7.9 \%$ vs $7.7 \% ; \mathrm{P}=0.99)$ and median length of stay (11 vs 11 days; $P=0.99$ ) were similar between men and women. However, median hospital charges were higher for men ( $\$ 166000$ vs $\$ 155000$; $\mathrm{P}=0.04$ ).

Conclusion Isolated TV surgery is rare, but women more commonly undergo the procedure. In-hospital mortality was similar between men and women after propensity matching, but remains markedly high for both men and women in comparison to that reported for left-sided isolated valve surgery.

\section{INTRODUCTION}

Tricuspid regurgitation (TR) is common in the USA and predominantly affects women. ${ }^{1-3}$ Tricuspid stenosis (TS) is extremely uncommon, particularly in the absence of concurrent congenital heart disease, or rheumatic mitral or aortic valve disease. ${ }^{3-6}$ Whatever the cause, isolated tricuspid valve (TV) disease can adversely affect long-term survival. ${ }^{4}$ Although medical therapy is often appropriate during the early stages of disease, surgical correction remains the only definitive treatment for refractory TV disease. ${ }^{8}$ However, isolated TV surgery is performed

\section{Key questions}

What is already known about this subject?

- Female sex is a known risk factor for in-hospital mortality following cardiac surgery.

- Tricuspid valve (TV) disease shows a predominance in women. Isolated TV surgery carries a high in-hospital mortality, but little is known about whether sex of the patient influences outcomes, as seen in most other cardiac surgical procedures.

What does this study add?

- The study shows that women have more commonly undergone isolated TV surgery in the USA and that the procedural volume is increasing over the 10-year study period.

- Women were found to have a higher rate of prior sternotomy, which usually leads to worse surgical outcomes.

- Despite significant baseline differences in baseline and surgical characteristics, including risk factors traditionally associated with higher cardiac surgical mortality, our results did not reveal any difference in mortality or postoperative complications between men and women undergoing isolated TV surgery in the USA.

How might this impact on clinical practice?

- Unlike other cardiac surgical procedures, our study suggests that female sex may not be needed to be taken into consideration as an independent risk factor for isolated TV surgery.

- Mortality was exceedingly high for both men and women, thus the optimal timing of the procedure should be carefully considered.

far less frequently than left-sided valve operations. ${ }^{9}$ Female sex is a known risk factor for hospital mortality and postoperative complications, and thus is included in established cardiac surgical risk models. ${ }^{10} 11$ Previous observational cohort studies of isolated TV surgery report high rates of in-hospital mortality ranging from $2 \%$ to $24 \%$, with the majority of patients referred for surgery being female. ${ }^{9} 12-15$ Despite difference in 


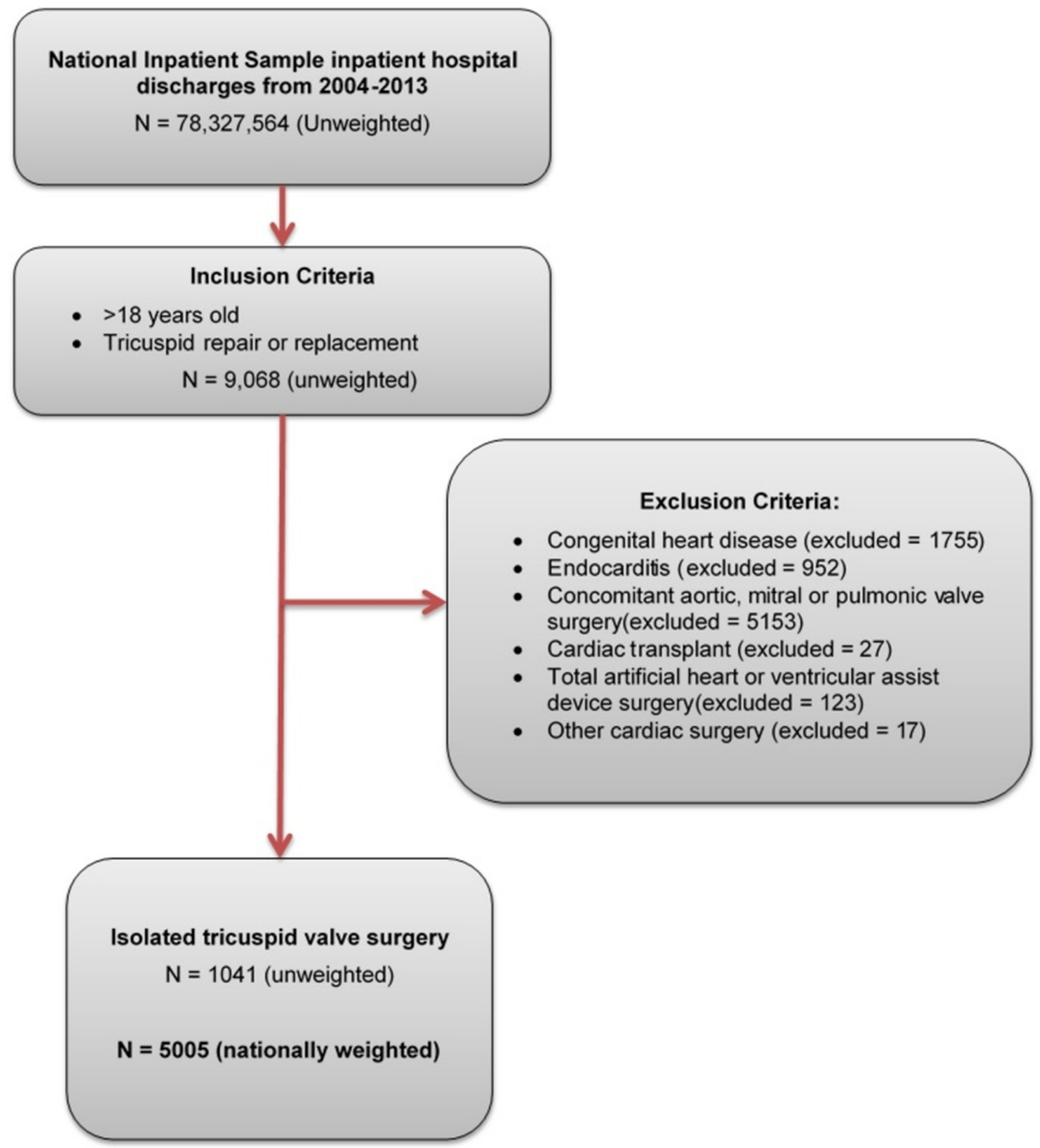

Figure 1 Sample selection methodology.

disease prevalence and surgical referral between men and women there has been a lack of attention to potential sex differences in surgical outcomes for TV surgery. ${ }^{16}$ In men and women undergoing isolated TV surgery, we hypothesised that women are more likely than men to experience in-hospital mortality. Due to the rarity of TV surgery, we decided to use a large multicentre database, the National Inpatient Sample (NIS).

\section{METHODS}

\section{Data source}

Data were obtained from the Agency for Healthcare and Research and Quality Healthcare Cost and Utilization Project NIS files from 1 January 2004 to 31 December 2013. The NIS is the largest publicly available all-payer administrative claims database. It contains deidentified patient and clinical data from approximately 1000 non-federal hospitals in 45 states, including approximately 5-8 million discharges annually. These data represent roughly $20 \%$ of hospital admissions in the USA and the collection of data is stratified to ensure equal representation of hospitals by geographic region, urban and rural locations, teaching status and hospital bed size. Data can be weighted such that the results can be extrapolated as representative of the entire US inpatient population. Procedure and diagnostic codes are recorded using International Classification of Diseases, Ninth Revision, Clinical Modification (ICD-9-CM). This study was exempt from Institutional Review Board evaluation and was supported in part by grants from the National Institutes of Health (National Center for Advancing Translational Sciences grant numbers UL1 TR000135 and P50 AG044170 to VMM).

\section{Study population}

Using ICD-9-CM codes, adults ( $>18$ years) were identified who underwent TV repair or replacement (mechanical or bioprosthetic) without concomitant aortic, mitral or 


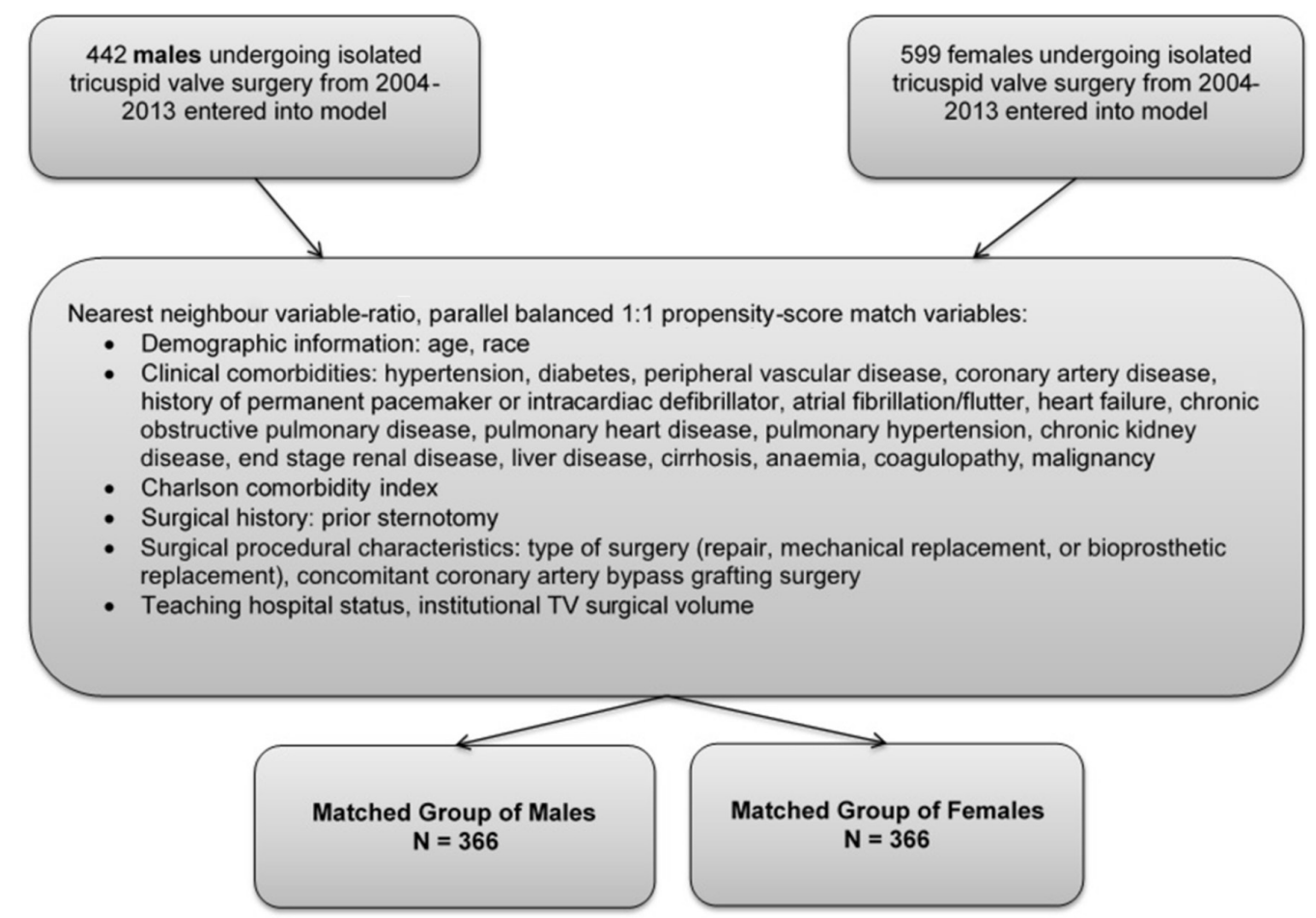

Figure 2 Propensity score matching algorithm to create groups of men and women matched on demographic, clinical and procedural characteristics. TV, tricuspid valve.

pulmonary valve surgery (figure 1) (online supplementary table 1). Those undergoing isolated TV surgery, with or without coronary artery bypass graft (CABG) surgery, were included. Concomitant CABG was included to represent patients with coronary artery disease (CAD) identified on preoperative angiography and it was felt that this inclusion criterion would best represent the population seen in clinical practice. Patients receiving TV surgery combined with aortic or pericardial surgery, orthotopic heart transplant, atrial or ventricular septal defect closure, or ventricular assist device implantation were excluded. We excluded patients with any diagnosis of congenital heart disease as they represent a fundamentally different patient population. We also excluded patients with a diagnosis of endocarditis as surgery is typically performed to control the infection and not to address valvular disease. Additional information on the cause of TV disease or specific indication for surgery (ie, valvular regurgitation vs stenosis) could not be determined due to limitations in the granularity of ICD-9-CM codes.

The primary outcomes of interest included a sex-stratified analysis of in-hospital mortality and postoperative complications. Secondary outcomes included sex-stratified trends in surgical volume over time, type of surgery performed (repair vs replacement), total cost of hospitalisation, length of hospital stay and discharge destination. Total cost of hospitalisation was determined from ICD-9-CM billing code charges that have been abstracted in the NIS database.

\section{Comparative outcomes analysis of men versus women}

A sex-stratified analysis was performed to determine if sex impacts TV surgical outcomes. To account for potential confounding factors and to reduce the effect of selection bias, a propensity score matching model using logistic regression (based on the propensity to be female) was derived to match men and women for comparative analysis. Men and women were matched 1:1 after being entered into a nearest neighbour 1:1 variable ratio parallel balanced propensity score matching model using a calliper width of $0.05 .{ }^{17}$ Propensity scores were derived using demographic variables, baseline comorbidities and the type of surgery (repair, replacement and concomitant $\mathrm{CABG}$ ) (figure 2).

\section{Statistical analysis}

Descriptive statistics are presented as frequencies with percentages for categorical variables. Continuous data are reported as a mean with $\mathrm{SD}$, or median with IQR, as appropriate for the data distribution. Baseline characteristics were compared between groups using a Pearson $\chi^{2}$ test or Fisher's exact test when expected counts were less than 5 for categorical variables, and using a t-test or Wilcoxon rank-sum for continuous variables. Matched categorical variables were compared using McNemar's test or an exact binomial test, and matched continuous variables were compared using a paired samples t-test. Unweighted NIS counts were used for all statistical analyses except trend assessments where nationally weighted estimates were used. A Cochran-Armitage test was used to evaluate trends in isolated TV surgery over time. The $\chi^{2}$ test of independence was used to establish differences in proportions for multiple groups.

All statistical analyses were performed using SPSS V.22 (IBM) and SAS V.9.3. A two-sided threshold of significance was established at $\mathrm{P}<0.05$. 
Table 1 Characteristics of patients undergoing isolated tricuspid valve surgery from 2004 to 2013

\begin{tabular}{|c|c|c|c|c|}
\hline & $\begin{array}{l}\text { Total } \\
(n=1041)\end{array}$ & $\begin{array}{l}\text { Men } \\
(n=442)\end{array}$ & $\begin{array}{l}\text { Women } \\
(n=599)\end{array}$ & $P$ value \\
\hline Age, mean $\pm S D$ & $58.9 \pm 16.8$ & $58.3 \pm 17.6$ & $59.4 \pm 16.2$ & 0.30 \\
\hline \multicolumn{5}{|l|}{ Race, n (\%) } \\
\hline Caucasian & $606(58.2)$ & $256(57.9)$ & $350(58.4)$ & 0.95 \\
\hline African American & $101(9.7)$ & $45(10.2)$ & $56(9.3)$ & \\
\hline Hispanic & $59(5.7)$ & $24(5.4)$ & $35(5.8)$ & \\
\hline Teaching hospital, n (\%) & $892(85.7)$ & $381(86.2)$ & $511(85.3)$ & 0.69 \\
\hline \multicolumn{5}{|l|}{ Medical comorbidity, n (\%) } \\
\hline Hypertension & $512(49.2)$ & $201(45.5)$ & $311(51.9)$ & 0.04 \\
\hline Diabetes & $208(20.0)$ & $84(19.0)$ & $124(20.7)$ & 0.50 \\
\hline Coronary artery disease & $350(33.6)$ & $178(40.3)$ & $172(28.7)$ & $<0.001$ \\
\hline Pacemaker*/intracardiac defibrillator & $116(11.1)$ & $52(11.8)$ & $64(10.7)$ & 0.58 \\
\hline Atrial fibrillation/flutter & $517(49.7)$ & $208(47.1)$ & $309(51.6)$ & 0.15 \\
\hline Pulmonary hypertension & $238(22.9)$ & $95(21.5)$ & $143(23.9)$ & 0.37 \\
\hline Chronic kidney disease & $197(18.9)$ & $105(23.8)$ & $92(15.4)$ & $<0.0001$ \\
\hline End-stage renal disease & $59(5.7)$ & $34(7.7)$ & $25(4.2)$ & 0.02 \\
\hline Cirrhosis & $41(3.9)$ & $20(4.5)$ & $21(3.5)$ & 0.40 \\
\hline Charlson comorbidity index $\geq 2$ & $597(57.3)$ & $266(60.2)$ & $331(55.3)$ & 0.11 \\
\hline Prior sternotomy, n (\%) & $130(12.5)$ & $43(9.7)$ & $87(14.5)$ & 0.02 \\
\hline Prior valve surgery, n (\%) & $98(9.4)$ & $23(5.2)$ & 75 (12.5) & $<0.0001$ \\
\hline Prior CABG, n (\%) & $34(3.3)$ & $21(4.8)$ & $13(2.2)$ & 0.02 \\
\hline \multicolumn{5}{|l|}{ Surgical characteristics, n (\%) } \\
\hline TV replacement-mechanical & $242(23.2)$ & $93(21.0)$ & $149(24.9)$ & 0.15 \\
\hline TV replacement—bioprosthetic & $374(35.9)$ & $162(36.7)$ & $212(35.4)$ & 0.68 \\
\hline TV repair & $425(40.8)$ & $187(42.3)$ & $238(39.7)$ & 0.40 \\
\hline Concomitant CABG & $208(20.0)$ & $112(25.3)$ & $96(16.0)$ & $<0.0001$ \\
\hline
\end{tabular}

*Permanent pacemaker.

CABG, coronary artery bypass graft surgery; TV, tricuspid valve.

\section{RESULTS}

\section{Baseline characteristics of the study population and differences between men and women}

Over the 10-year period from January 2004 to December 2013, there were a total of 5005 admissions (nationally weighted) for isolated TV surgery. The majority of patients were female (2878 women $(57.5 \%), 2127$ men $(42.5 \%))$. The mean age for all patients was $58.9 \pm 16.8$ years (table 1). Men had a greater number of comorbidities when compared with women including CAD $(40.3 \%$ vs $28.7 \%, \mathrm{P}<0.001)$, chronic kidney disease $(23.8 \%$ vs $15.4 \%, \mathrm{P}<0.0001)$ and end-stage renal disease $(7.7 \%$ vs $4.2 \%, \mathrm{P}=0.02)$. Men were more likely to have received previous $\mathrm{CABG}$ ( $4.8 \%$ vs $2.2 \%, \mathrm{P}=0.02$ ), as well as undergo concomitant $\mathrm{CABG}$ during their TV surgery $(25.3 \%$ vs $16.0 \%, \mathrm{P}<0.0001)$. Women, however, were more likely to be hypertensive ( $51.9 \%$ vs $45.5 \%$; $\mathrm{P}=0.04$ ) and more likely to have had a previous valve surgery $(5.2 \%$ vs $12.5 \%$, $\mathrm{P}<0.0001)$.
The number of procedures significantly increased over the study period from 290 procedures in 2004 to 780 procedures in 2013 (nationally weighted estimates, $\mathrm{P}<0.0001$ for trends) with women consistently making up the majority of the surgical volume each year. TV replacement was the predominant type of surgery, being performed in $57.7 \%$ of men and $60.3 \%$ of women. Of all the TV replacements, $60.7 \%$ were replaced using a bioprosthetic valve and $39.3 \%$ received a mechanical valve.

In-hospital mortality was not significantly different between unmatched men and women $(9.8 \%$ vs $8.2 \%$, $\mathrm{P}=0.38$ ). Among the subgroup of patients who experienced in-hospital mortality, the median time from the date of surgery to date of death was 13 days for men and 18 days for women $(\mathrm{P}=0.06)$. There were no significant differences between the postoperative complications in the unmatched cohort (online supplementary table 2). There remained no difference when further stratifying by type of TV surgery. 
Table 2 Baseline characteristics of propensity-matched men and women undergoing isolated tricuspid valve surgery from 2004 to 2013

\begin{tabular}{|c|c|c|c|}
\hline & $\begin{array}{l}\text { Men } \\
(n=366)\end{array}$ & $\begin{array}{l}\text { Women } \\
(\mathrm{n}=366)\end{array}$ & $\begin{array}{l}P \\
\text { value }\end{array}$ \\
\hline Age, mean $\pm S D$ & $57.9 \pm 18.1$ & $57.6 \pm 17.2$ & 0.86 \\
\hline \multicolumn{4}{|l|}{ Race, n (\%) } \\
\hline Caucasian & $212(57.9)$ & $217(59.3)$ & 0.88 \\
\hline African American & $36(9.8)$ & $35(9.6)$ & \\
\hline Hispanic & $22(6.0)$ & $18(4.9)$ & \\
\hline Teaching hospital, n (\%) & $314(85.8)$ & $315(86.1)$ & 0.99 \\
\hline \multicolumn{4}{|l|}{ Medical comorbidity, n (\%) } \\
\hline Hypertension & $175(47.8)$ & $171(46.7)$ & 0.82 \\
\hline Diabetes & $66(18.0)$ & $68(18.6)$ & 0.92 \\
\hline Coronary artery disease & $126(34.4)$ & $122(33.3)$ & 0.80 \\
\hline Atrial fibrillation/flutter & $180(49.2)$ & $175(47.8)$ & 0.76 \\
\hline $\begin{array}{l}\text { History of permanent } \\
\text { pacemaker/ICD }\end{array}$ & $45(12.3)$ & $36(9.8)$ & 0.35 \\
\hline Pulmonary hypertension & $81(22.1)$ & $86(23.5)$ & 0.72 \\
\hline $\begin{array}{l}\text { Chronic pulmonary } \\
\text { disease }\end{array}$ & $56(15.3)$ & $54(14.8)$ & 0.92 \\
\hline Anaemia & $67(18.3)$ & $71(19.4)$ & 0.77 \\
\hline Chronic kidney disease & $71(19.4)$ & $71(19.4)$ & 0.99 \\
\hline End-stage renal disease & $22(6.0)$ & $20(5.5)$ & 0.86 \\
\hline Liver disease & $24(6.6)$ & $24(6.6)$ & 0.99 \\
\hline $\begin{array}{l}\text { Charlson comorbidity } \\
\text { index } \geq 2\end{array}$ & $208(56.8)$ & $200(54.6)$ & 0.56 \\
\hline Prior sternotomy, n (\%) & $39(10.7)$ & $39(10.7)$ & 0.99 \\
\hline Prior valve surgery, $\mathrm{n}(\%)$ & $22(6.0)$ & $32(8.7)$ & 0.21 \\
\hline
\end{tabular}

Surgical characteristics, $\mathrm{n}$

(\%)

\begin{tabular}{lrrr}
$\begin{array}{l}\text { TV replacement- } \\
\text { mechanical }\end{array}$ & $81(22.1)$ & $79(21.6)$ & 0.93 \\
$\begin{array}{l}\text { TV replacement- } \\
\text { bioprosthetic }\end{array}$ & $138(37.7)$ & $136(37.2)$ & 0.88 \\
\hline $\begin{array}{l}\text { TV repair } \\
\text { Concomitant CABG }\end{array}$ & $147(40.2)$ & $151(41.3)$ & 0.83 \\
\hline
\end{tabular}

CABG, coronary artery bypass graft surgery; ICD, implantable cardiac defibrillator; TV, tricuspid valve.

\section{Sex-stratified outcomes after propensity matching}

To account for the effect of baseline and operative differences on mortality between sexes, propensity score matching was performed, resulting in two matched groups of 366 men and 366 women. Baseline comorbidities and surgical characteristics of the matched groups are described in table 2. The standardised difference for all variables was less than $10 \%$ indicating a successful balance in covariates between men and women (figure 3). After matching, men and women experienced similar clinical outcomes including in-hospital mortality $(7.9 \%$ vs $7.7 \%$, $\mathrm{P}=0.99$ ), length of stay ( 11 days vs 11 days, $\mathrm{P}=0.99$ ) and postoperative complications (table 3). Hospital charges for men were significantly higher than charges for women ( $\$ 166000$ vs $\$ 155000, \mathrm{P}=0.04$ ) despite matching on surgical characteristics including concomitant CABG and type of TV surgery.

Propensity matching on a large number of variables can lead to loss of randomness in the selection process and overfitting the model such that the results have limited external generalisability. ${ }^{18}$ Therefore, we performed two sensitivity analyses. First, the model was run using a propensity score model containing only the clinically relevant variables (online supplementary tables 3 and 4). This analysis did not alter our initial findings. Next we performed inverse probability of treatment weighting using the propensity score to weight each man and woman accordingly. ${ }^{17}$ Using this weighting the OR for a woman to experience in-hospital mortality compared with a man was found to be not significant (OR: 0.849, $95 \%$ CI 0.543 to $1.327 ; \mathrm{P}=0.47$ ).

\section{DISCUSSION}

There are sex differences in the prevalence of TV disease with women showing a clear predominance. ${ }^{1-4}$ In one single-centre cohort study, women made up $64 \%$ of subjects with severe TV regurgitation, whereas in the Framingham Offspring Study women made up $62 \%$ of patients with more than moderate TV regurgitation. ${ }^{12}$ While TS is uncommon, women also make up the largest group of patients with TS. ${ }^{4}$ In a surgical registry of patients with both TR and TS, $66 \%$ of patients were female. ${ }^{3}$ However, despite the well-established prevalence of TV disease in women, a pathophysiological reason for this sex difference remains to be described.

Several studies have addressed the impact of female sex on cardiac surgical outcomes. In one series, women undergoing CABG experienced significantly worse in-hospital mortality compared with men. ${ }^{19}$ In a second study, female sex was further found to be an independent risk factor for adverse outcomes in patients undergoing combined valve and CABG surgery. ${ }^{20}$ Rankin et al analysed over 400000 valvular surgeries in the Society of Thoracic Surgeons (STS) database from 1994 to 2003 and found that female sex associated with a higher mortality. ${ }^{21}$ Increased surgical risk in women has been attributed to less favourable operative risk profiles and smaller body size compared with men. In both the Society for Thoracic Surgeons cardiac surgical risk model and the EuroScore II risk model, female sex has been incorporated into the model as a significant predictor of increased in-hospital mortality. ${ }^{11}$ However, in these surgical risk model studies, TV surgery only consisted of anywhere from $0 \%$ to $5 \%$ of the study sample. Leviner et al found female sex to be a univariate predictor of operative mortality following TV replacement as well as a significantly lower 5 -year survival rate. ${ }^{16}$ Despite the higher prevalence of TV disease in women and sex being a risk factor for morbidity and mortality following cardiac surgery, there 


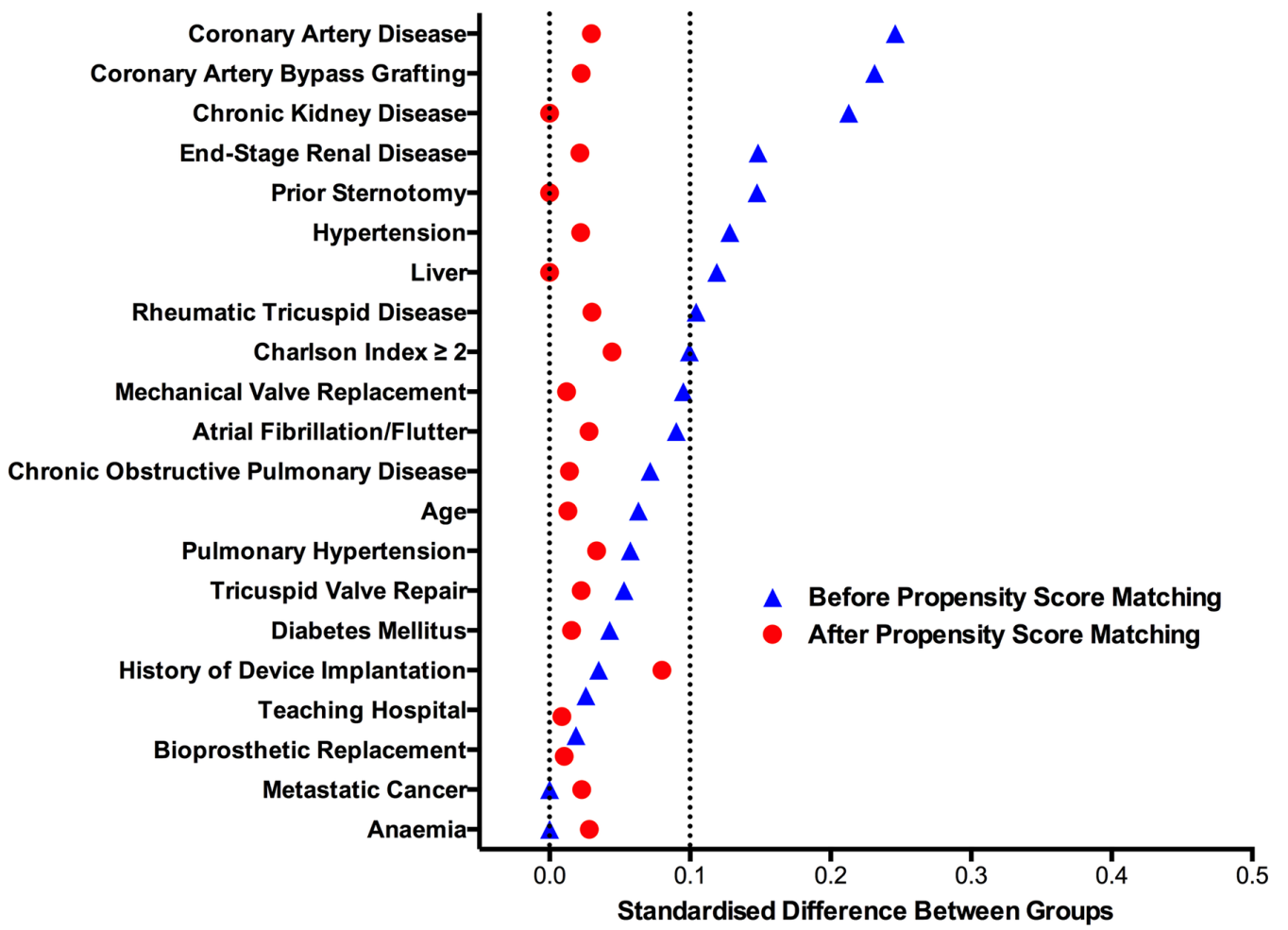

Figure 3 Standardised differences in variables before and after propensity score matching. The standardised difference between groups of men and women is represented on the $\mathrm{x}$-axis for each variable on the $y$-axis. After propensity matching all standardised differences were less than $10 \%$, indicating well-balanced groups of men and women.

are very few previous studies examining the impact of sex on TV surgical outcomes. ${ }^{11} 19$

In the current study, we found that surgery was more frequently performed in women, but that men and women experienced similar rates of postoperative complications and mortality. Women were less likely to have $\mathrm{CAD}$ and therefore were less likely to receive concomitant CABG, which suggests women may be more likely to be referred for isolated TV surgery without another indication. ${ }^{22}{ }^{23}$ Even after correcting for differences in CABG rates between men and women by propensity matching, hospitalisation costs remained significantly higher in men. This difference in cost was not explained by resource utilisation or length of stay, and is an area for

Table 3 In-hospital outcomes of propensity-matched men and women undergoing isolated tricuspid valve surgery from 2004 to 2013

\begin{tabular}{lccc}
\hline & $\begin{array}{l}\text { Men } \\
(\mathbf{n}=366)\end{array}$ & $\begin{array}{l}\text { Women } \\
(\mathbf{n = 3 6 6 )}\end{array}$ & $\mathbf{P}^{*}$ value \\
\hline Clinical outcome, $n$ (\%) & $29(7.9)$ & $28(7.7)$ & 0.99 \\
\hline In-hospital mortality & $27(7.4)$ & $22(6.0)$ & 0.54 \\
\hline Cardiogenic shock & $102(27.9)$ & $88(24.0)$ & 0.26 \\
\hline Permanent pacemaker implantation & $5(1.3)$ & $10(2.7)$ & 0.30 \\
\hline Acute cerebrovascular accident & $113(30.9)$ & $93(25.4)$ & 0.12 \\
\hline Acute kidney injury & $15(4.1)$ & $15(4.1)$ & 0.99 \\
\hline Acute kidney injury requiring dialysis & $126(34.4)$ & $141(38.5)$ & 0.30 \\
\hline Blood transfusion & & & 0.62 \\
\hline Discharge status, $n$ (\%) & $261(71.3)$ & $257(70.2)$ & \\
\hline Discharged home & $71(19.4)$ & $79(21.6)$ & 0.99 \\
\hline DischargedIC/NH/SNF & $11(7-21)$ & $11(7-20)$ & 0.04 \\
\hline Length of stay, median (IQR), days & $166(107-276)$ & $155(102-241)$ & \\
\hline Hospital charges, median (IQR), $\times \$ 1000$ & & & \\
\hline
\end{tabular}

*For small sample sizes an exact binomial test was used in place of McNemar's test.

IC, intermediate care facility; $\mathrm{NH}$, nursing home; SNF, skilled nursing facility; IQR, interquartile range. 
further investigation, possibly with more granular data on hospital charges.

We found that women who underwent isolated TV surgery were more likely to have had a prior valve surgery. This finding is in concordance with previous studies that have observed that women are more likely to develop late significant TV regurgitation following left-sided surgery compared with men. ${ }^{24} 25$ The reason for this observation is not yet clear; however, it may be that women are prone to developing a higher transprosthetic mean gradient compared with men or to the higher prevalence of rheumatic disease in women. ${ }^{26} 27$ Regardless, this finding suggests that closer observation for the development of late TV regurgitation could be considered in women following left-sided valve surgery.

While we did not note a significant difference in operative outcomes by patient sex, it is important to note that overall surgical mortality was high. In-hospital mortality of left-sided valve surgery from a similar national database is reported to be approximately $4 \%-5 \% .{ }^{28}{ }^{29}$ With operative mortality of isolated TV surgery being almost double, further research into optimal patient selection and timing of surgery is needed to improve the safety of isolated TV surgery. Additionally, lower risk alternatives to surgery for symptomatic patients including percutaneous approaches should be explored with appropriate emphasis on analysis by sex and gender.

\section{Limitations}

This study has several limitations. First, the NIS is an administrative database which classifies patients and procedures according to ICD-9-CM codes and therefore may be prone to coding errors. The NIS attempts to mitigate potential errors by using internal and external quality control measures. Second, the use of ICD-9-CM codes limits the type of data that can be collected. ICD-9 codes do not distinguish between TS and TR. Therefore, it is not possible to know if the procedure was performed for TS or TR. However, due to the extreme rarity of isolated TS, it can be assumed that the majority of cases were performed for TR. There are also no reliable billing codes for variables that can be traditionally associated with cardiac outcomes including data on smoking, body weight and left ventricular function. Hence, these variables could not be included in the comparative analysis. Third, as our definition of isolated TV surgery included concomitant CABG and due to the lack of granularity with regard to the indication for surgery, some of the included surgeries might have been primarily for CAD rather than TV disease. However, we performed a sensitivity analysis, removing those who underwent CABG and had a primary diagnosis listed as CAD, which did not reveal any difference in outcomes. Finally, longterm follow-up cannot be performed using the NIS. Despite these limitations, this study fills an important gap in the literature by assessing surgical morbidity and mortality by sex.

\section{CONCLUSION}

The number of isolated TV surgeries for both men and women is rising, with women making a majority of the surgical volume. Despite adjustment for higher rates of CABG in men, the average hospital charges for men remained higher than for women. Adjusted mortality did not vary according to sex, contrary to the stated hypothesis. Mortality rates are high for both men and women, and are greater than what has been reported for leftsided valve surgeries.

Acknowledgements This manuscript was written in partial fulfilment of requirements for the Mayo Clinic Graduate School of Medicine Biomedical Engineering (BME) 6855 Tutorial in Cardiovascular Physiology course.

Contributors PC, EAF, CJZ: conception and design; acquisition, analysis and interpretation of data for the work; drafting and revision of the article. YNVR, CEB, MP, MAA: conception and design; analysis and interpretation of data for the work; revision of manuscript. JMS: critical revision of manuscript for intellectual content. VMM: conception and design; critical revision of manuscript for intellectual content; final approval of the manuscript. All authors contributed significantly to data collection, analysis and drafting of the manuscript, are in agreement to be accountable for all aspects of the work, and have read and approved the final article.

Funding This publication was made possible by NIH P50 AG044170 and by CTSA (grant number UL1 TR000135) from the National Center for Advancing Translational Sciences (NCATS), a component of the National Institutes of Health (NIH). Its contents are solely the responsibility of the authors and do not necessarily represent the official view of $\mathrm{NIH}$.

Competing interests None declared.

Provenance and peer review Not commissioned; internally peer reviewed.

Data sharing statement No additional data are available.

Open Access This is an Open Access article distributed in accordance with the Creative Commons Attribution Non Commercial (CC BY-NC 4.0) license, which permits others to distribute, remix, adapt, build upon this work non-commercially, and license their derivative works on different terms, provided the original work is properly cited and the use is non-commercial. See: http://creativecommons.org/ licenses/by-nc/4.0/

(C) Article author(s) (or their employer(s) unless otherwise stated in the text of the article) 2018. All rights reserved. No commercial use is permitted unless otherwise expressly granted.

\section{REFERENCES}

1. Singh JP, Evans JC, Levy D, et al. Prevalence and clinical determinants of mitral, tricuspid, and aortic regurgitation (the Framingham heart study). Am J Cardiol 1999;83:897-902.

2. Ong K, Yu G, Jue J. Prevalence and spectrum of conditions associated with severe tricuspid regurgitation. Echocardiography 2014;31:558-62.

3. Hauck AJ, Freeman DP, Ackermann DM, et al. Surgical pathology of the tricuspid valve: a study of 363 cases spanning 25 years. Mayo Clin Proc 1988;63:851-63.

4. Roguin A, Rinkevich D, Milo S, et al. Long-term follow-up of patients with severe rheumatic tricuspid stenosis. Am Heart $J$ 1998;136:103-8.

5. Sharma S, Loya YS, Desai DM, et al. Percutaneous double-valve balloon valvotomy for multivalve stenosis: immediate results and intermediate-term follow-up. Am Heart J 1997;133:64-70.

6. Bruce CJ, Connolly HM. Right-sided valve disease deserves a little more respect. Circulation 2009;119:2726-34.

7. Topilsky Y, Nkomo VT, Vatury O, et al. Clinical outcome of isolated tricuspid regurgitation. JACC Cardiovasc Imaging 2014;7:1185-94.

8. Shinn SH, Schaff HV. Evidence-based surgical management of acquired tricuspid valve disease. Nat Rev Cardiol 2013;10:190-203.

9. Kilic A, Saha-Chaudhuri P, Rankin JS, et al. Trends and outcomes of tricuspid valve surgery in North America: an analysis of more than 50,000 patients from the society of thoracic surgeons database. Ann Thorac Surg 2013;96:1546-52.

10. Nashef SA, Roques F, Sharples LD, et al. EuroSCORE II. Eur J Cardiothorac Surg 2012;41:734-45. 
11. O'Brien SM, Shahian DM, Filardo G, et al. The society of thoracic surgeons 2008 cardiac surgery risk models: part 2--isolated valve surgery. Ann Thorac Surg 2009;88(1 Suppl):S23-42.

12. Kim JB, Jung SH, Choo SJ, et al. Clinical and echocardiographic outcomes after surgery for severe isolated tricuspid regurgitation. J Thorac Cardiovasc Surg 2013;146:278-84.

13. Ratnatunga CP, Edwards MB, Dore CJ, et al. Tricuspid valve replacement: UK heart valve registry mid-term results comparing mechanical and biological prostheses. Ann Thorac Surg 1998;66:1940-7.

14. Moraca RJ, Moon MR, Lawton JS, et al. Outcomes of tricuspid valve repair and replacement: a propensity analysis. Ann Thorac Surg 2009;87:83-9.

15. Singh SK, Tang GH, Maganti MD, et al. Midterm outcomes of tricuspid valve repair versus replacement for organic tricuspid disease. Ann Thorac Surg 2006;82:1735-41.

16. Leviner DB, Medalion B, Baruch I, et al. Tricuspid valve replacement: the effect of gender on operative results. J Heart Valve Dis 2014;23:209-15.

17. Austin PC. An introduction to propensity score methods for reducing the effects of confounding in observational studies. Multivariate Behav Res 2011;46:399-424.

18. Augurzky B, Schmidt CM. The propensity score: a means to an end, 2001

19. Fox AA, Nussmeier NA. Does gender influence the likelihood or types of complications following cardiac surgery? Semin Cardiothorac Vasc Anesth 2004;8:283-95.

20. Ibrahim MF, Paparella D, Ivanov J, et al. Gender-related differences in morbidity and mortality during combined valve and coronary surgery. J Thorac Cardiovasc Surg 2003;126:959-64.
21. Rankin JS, Hammill BG, Ferguson TB, et al. Determinants of operative mortality in valvular heart surgery. $J$ Thorac Cardiovasc Surg 2006;131:547-57.

22. Matsunaga A, Duran CM. Progression of tricuspid regurgitation after repaired functional ischemic mitral regurgitation. Circulation 2005;112(9 Suppl)::1453-7.

23. Izumi $\mathrm{C}$, Iga $\mathrm{K}$, Konishi T. Progression of isolated tricuspid regurgitation late after mitral valve surgery for rheumatic mitral valve disease. J Heart Valve Dis 2002;11:353-6.

24. Song $\mathrm{H}$, Kim MJ, Chung $\mathrm{CH}$, et al. Factors associated with development of late significant tricuspid regurgitation after successful left-sided valve surgery. Heart 2009;95:931-6.

25. Jeong DS, Sung K, Kim WS, et al. Fate of functional tricuspid regurgitation in aortic stenosis after aortic valve replacement. J Thorac Cardiovasc Surg 2014;148:1328-33.

26. Jeong DS, Park PW, Sung K, et al. Determinants of late tricuspid regurgitation after aortic-mitral double valve replacement. Am J Cardiol 2017:119:1643-9.

27. Teshima H, Fukunaga S, Takaseya T, et al. Obstruction of St. Jude medical valves in the aortic position: plasma transforming growth factor type beta 1 in patients with pannus overgrowth. Artif Organs 2010;34:210-5.

28. Kilic A, Shah AS, Conte JV, et al. Operative outcomes in mitral valve surgery: combined effect of surgeon and hospital volume in a population-based analysis. J Thorac Cardiovasc Surg 2013;146:638-46.

29. Agarwal S, Garg A, Parashar A, et al. In-hospital mortality and stroke after surgical aortic valve replacement: a nationwide perspective. J Thorac Cardiovasc Surg 2015;150:571-8. 